\title{
Research on the Innovative Application of Fabric Art Decoration in Home Space Design
}

\author{
Lili Sun \\ School of Design and Art \\ Harbin University of Commerce \\ Harbin, China
}

\begin{abstract}
With unique expressive force, fabric art decoration plays a crucial role in home space design. based on the characteristics of fabric art decoration, this paper analyzes its innovative application from space shaping, color creation and material selection, so as to provide references for design and application of fabric art decoration in room design.
\end{abstract}

Keywords-fabric art decoration; home furnishing; design; application

\section{INTRODUCTION}

Home space gathers emotions of people. Designers shall think more about people's emotional needs, including the requirements of each family member on details. Fabric art decoration can create living space with different atmospheres and design styles through unique expressive force. Decoration and practicality of fabric art is highlighted in home space, gradually becoming a trend.

\section{THE INNOVATIVE APPLICATION OF FABRIC ART DECORATION IN SPACE SHAPING}

Interior design emphasizes overall artistic effect. Although it has high requirements for design of elements, it is the priority among priorities to unify these requirements and shape overall space. It shall fully shows every part of home space and conforms to overall layout. The top priority is to integrate these unique parts. The continuity of interior space includes two parts: the first is continuity of modeling, color and material through each space interface; the second is people's psychological perception of spatial continuity. Fabric art decoration is a connecting link between the preceding and the following through strong plasticity, bright color and texture. It can create continuous space of psychological perception and meet people's physiological and psychological requirements for home space. In addition, fabric art decoration succeeds in attracting people's attention and forming continuous artistic effects of infinite extension in space.

\section{A. The Application of Fabric Art Decoration in Spatial Partition}

Interior decoration pays attention to privacy protection, collection of light and wall decoration. Different interior spaces have different requirements for privacy. There are many types of space partition. Fabric art partition with light texture, changeable modeling and multiple combination stands out in home decoration. In regard to the privacy of drawing room used for receiving visitors and gathering, designers can use soft partition of fabric art or semitransparent partition, because the design can absorb light, reduce exposure and extend the space. Because bedrooms and toilets are special and private, the fabric art partition shall be heavy and safe, reducing exposure through blocking the light. Dining rooms can be parted by wall, but it is protective and beautiful by using lace curtain. Diversified fabrics can be used to decorate the wall, providing great visual experience and impeding noise. Besides, soft fabric art partition can give people hazy beauty mentally.

\section{B. The Application of Fabric Art Decoration in Spatial Mobility}

Interior design especial home space design pursues spatial dynamics and rhythm sensation. According to the design principle, comfortable, harmonious fabric art decoration with rich information is the best choice. Fabric art design shall be "reasonable" and humanized, so as to meet people's requirements for spatial continuity and mobility. Soft fabric art resembles running water extending to all directions quietly. Continuous vitality extends along linear directions to realize rectilinear extension, full of strong expressive force "Fig. 1", "Fig. 2".

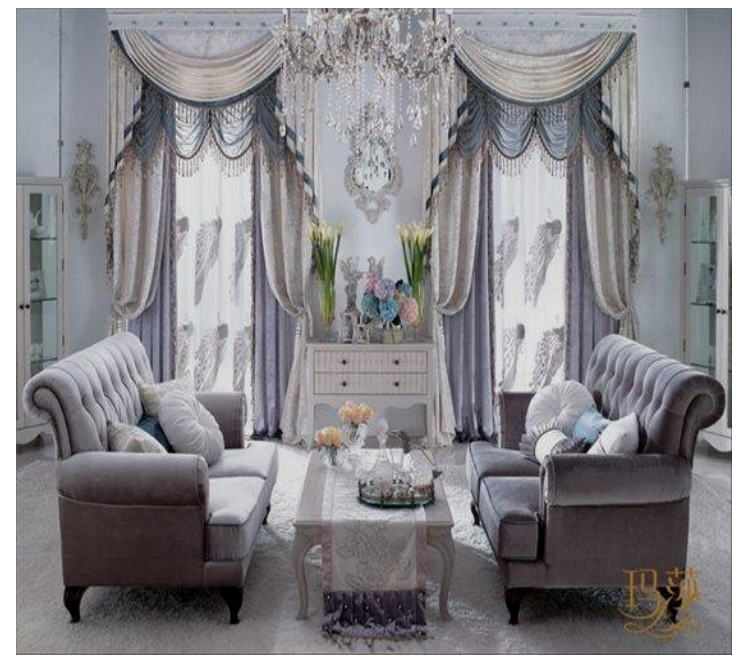

Fig. 1. The application of fabric art decoration in spatial mobility 


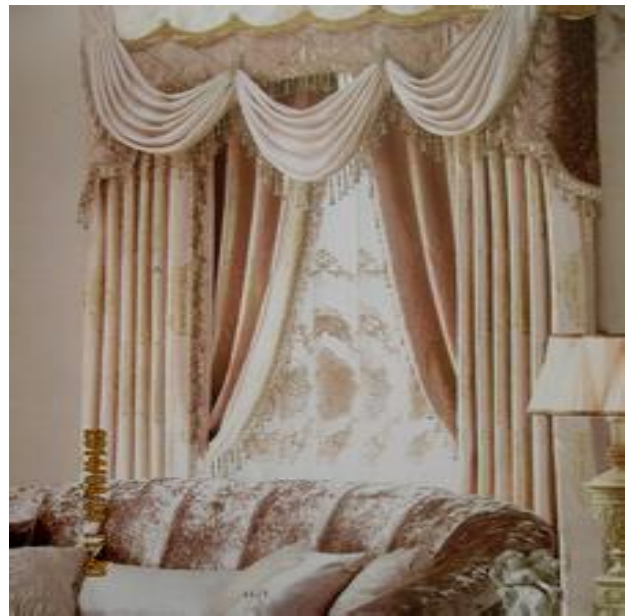

Fig. 2. The application of fabric art decoration in spatial mobility

\section{ThE INNOVATIVE APPLICATION OF FABRIC ART DECORATION IN COLOR CREATION}

Integration of emotions and scenery is a perfect design method. The selection of fabrics shall conform to overall home space environment. The design conception shall match with style of interior design. For example, edified by traditional Chinese culture, people often use a red bedding bag with character of $\mathrm{Xi}$ on Chinese wedding. It is obviously not appropriate to apply the design to Romanesque building design. Each style has its own matching principle. For example, in Chinese style design, red and yellow fabrics are often used to match with Chinese classical solid wood furniture; in design of pastoral style, fabrics with many small flowers are often used, including all kinds of fresh and tender "fruit" color representing nature "Fig. 3"; in design of western style, brightcolored fabrics are often presented, including deep and romantic luxurious color. Rosiness is often the best choice, like fabrics of "France's Versailles" series, which often use gold, red and purple as theme colors "Fig. 4"; in modern design style, figures on fabrics include square lattice and dot, combining modern elements of "point, line and plane". In design style of mini-nationalism, fabric colors have high purity with alternating red, yellow, blue and white.

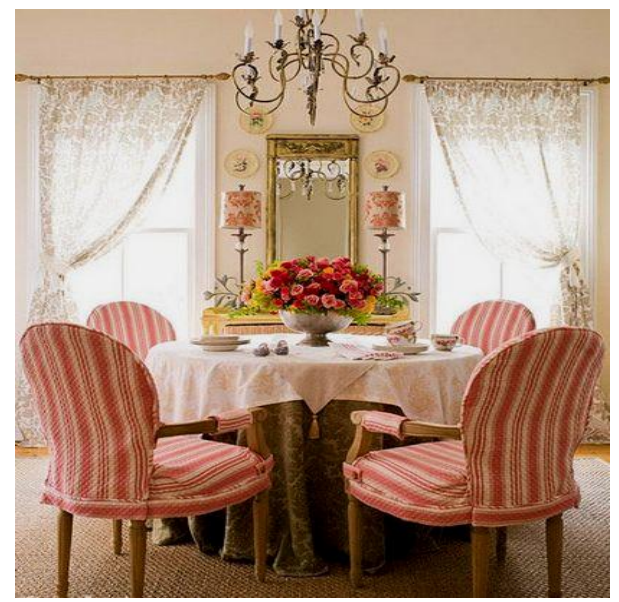

Fig. 3. The application of fabric art decoration in spatial mobility

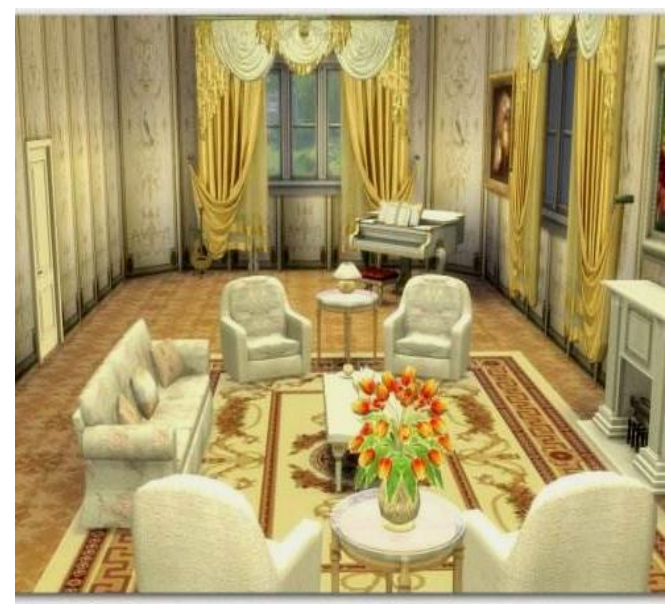

Fig. 4. The application of fabric art decoration in spatial mobility

\section{A. TheUnification and Contrast of Fabric Art Decoration}

In home space design, the design and color of curtain and sofa can be used to unify overall tone of living space. Designers often prefer to similar colors or adjacent color. But they shall avoid neglecting layering because of using the same color system. Designs of contrasting colors can be applied skillfully like using cool colors in warm southern areas and warm colors in the freezing northern areas. Flower colors of small areas can be used to create highlighted effects, like unique back cushions or colors different from fabric texture, so that it forms small areas of visual center, perfectly combining unification with contrast.

\section{B. The Scene Collocation of Fabric Art Decoration}

In modern fast-paced life, people increasingly yearn for a cozy space to have a rest after busy work. But the feeling of freshness cannot last. People often require different collocation of home space according to different time and seasons to keep fresh. On this occasion, the economic, fast and changeable fabric art decoration can exactly meet people's psychological requirements.

In spring, white or light colors are the main color. Grey white sofa made of linen fabric, back cushion of flower color, curtain with small flower color and chair cover of the same series can create the breath of spring. In summer, cool and refreshing colors are used. Fabrics of cool colors are used. Ocean blue alternates with white to present Mediterranean style, adding freshness indoors. Autumn and winter are the seasons of yellow and white. Brown and terracotta heavy curtains obstruct chill. Sofa and decorations of warm colors echo with it, creating warm interior atmosphere.

\section{ThE INNOVATIVE APPLICATION OF FABRIC ART DECORATION IN MATERIAL SELECTION}

\section{A. The Application of Gleamy and Exquisite Fabrics}

The texture of fabrics directly influences atmosphere of living space. The function division of different living space can be realized through fabrics. The function division of 
interior space can be strengthened through texture of fabrics. For example, many fabrics have complicated but not messy texture. Different layout can bring different visual and touching experience. The fabrics with gold and silver wire succeed in presenting gorgeous design. The living room that pursues light effects can use these fabrics. Bright and concise fabrics are also unique means to embody elegant style of dinning room. Furthermore, fabrics with exquisite texture and home style can bring out the best in each other. Colorful patterns of fabrics can be used in decoration of drawing room, showing theme of design style. Flashing fabrics can strengthen the reflection of sunshine, further expanding the space.

\section{B. The Application of Rough Wool Loose Fabrics}

In modern home space, rough wool loose fabrics will become fashionable, diversified and personalized instead of being countrified. In the consumption tide advocating green and return to nature, hand-made rough fabrics with simple folk patterns and old folk arts appeal to modern people. Rough wool loose fabrics have strong functional plasticity, showing peaceful space and slack characteristics. Velvet and wool can be used to absorb light, manifesting comfortable feeling and creating soft interior atmosphere.

\section{CONCLUSION}

The endless charm of fabric art decoration has been highlighted through the innovation of space modeling, color matching and material selection in living environment. In space modeling, it separates the space gently through its softness; in color creation, the interior spaces with different design styles, regions and seasons are created under the principle of unification and contrast by use of multiple colors of fabric art decoration; in material selection, different fabric materials are provided for people to create capacious, bright or rustic atmosphere.

\section{REFERENCES}

[1] Zhang Han. Interior Space Design [M], Beijing Science Press, 2008

[2] Wu Hao, Chen Shan. Flowing Space-Interior Space Design [M], China Building Industry Press, 2005

[3] Cui Wei. Artistic Design of Modern Interior Textiles [M], China Textile Press, 1999

[4] Stanley Abercrombie (America), Interior Design and Decoration [M], Tianjin University Press, 2006. 